\title{
Bite-count vs Fecal Analysis for Range Animal Diets
}

\author{
KENNETH D. SANDERS, BILL E. DAHL, AND GRETCHEN SCOTT
}

\section{Abstract}

This study indicated that the bite-count and fecal analysis methods give similar results for estimating major components of cattle diets in Texas. The bite-count method could not be used on large, brush-infested pastures with rough terrain; however, the fecal analysis metnod was easily used under such conditions. Other advantages of fecal analyses were: samples were collected with a minimum of field work, diets of wild and domestic animals could be obtained, and bad weather and poor field conditions were not problems. Major disadvantages of the fecal analysis technique were: forages with dense stellate trichomes were overestimated; mesquite beans were retained in the digestive tract for abnormally long periods; the laboratory phase required a trained technician; and the work was tedious.

Knowledge of the species consumed by grazing-animals, season by season, is fundamental to proper grazing management. Commonly used methods for obtaining diet composition have included: direct animal observation, forage utilization, and identification of plant material collected by esophageal fistula from stomach contents, or from fecal material. Many researchers consider the esophageal fistula technique the most accurate (Harris et al. 1959; Rice 1970), and Cook (1964) found it less time consuming than other methods. However, identification of individual grasses or individual forbs is often impossible with fistula collections. Because of the obvious disadvantages of working with fistulated animals in large pastures; areas with rough, rocky, terrain; or areas heavily infested with brush, other methods that offer reasonably accurate data are often needed.

Ideally, a method for determining grazing-animal diets will: (1) allow free animal movement and completely natural selection of all available plants and plant parts regardless of pasture size; (2) allow for diet determination regardless of

\footnotetext{
Authors are graduate research assistant, professor, and technician, Department of Range and Wildlife Management, Texas Tech University, Lubbock 79409. At present, Sanders is assistant professor, College of Forestry, Wildlife and Range Sciences, University of Idaho, Moscow.

This study is a contribution of the College of Agricultural Sciences, Texas Tech University No. T-9-161. The authors wish to thank R.A. Brown for his support during conduct of this study.

Manuscript received January 29, 1979
}

terrain; (3) be equally useful for wild and domesticated animals; (4) not require slaughter of test animals; (5) require a minimum of animal care; (6) be relatively objective; and (7) allow identification of each individual plant species consumed.

Microscopic examination of fecal material fits the criteria outlined. Baumgartner and Martin (1939) identified food items in squirrel diets more than 40 years ago by microscopic examination. More recently plant species consumed by sheep (Hercus 1960), cattle (Malechek 1966; Free et al. 1971), and horses (Regal 1960) were identified by examination of feces and/or rumen contents through a microscope. Unequal digestibility among plants (Regal 1960) appears the most serious source of error in determining diet composition from fecal examination. Also, the laboratory analysis method is tedious (Ward 1970).

A technique commonly used and that also meets the criteria outlined is a variation of the feeding-minutes method termed the "bite-count" method used by Reppert (1960) and McMahan (1964). Free et al. (1971) working with steers obtained diet information comparable to the esophageal fistula method using the bite-count technique.

Because of brush infestation and the rough topography of most Texas ranges, obtaining usable diet information for management or research purposes is a major problem. Despite its limitations, microscopic evaluation of diets from fecal material seems to offer a viable choice. Therefore, the objective of this study was to find out if the fecal examination by microscope technique could provide diet compositions similar to those obtained from the bite-count method.

\section{Methods}

The study was conducted in $1972-73$ on the R.A. Brown ranch in north-central Texas. Cattle diets were determined by the bitecount and fecal analysis methods at monthly intervals on two grazing systems, continuous yearlong use, and a short duration system. 
Diets obtained by bite-count were collected each month by observing five animals in each system. All animals had free access to all parts of the pasture. Each animal was individually observed for 10 to 20 minutes at a time at close range ( 3 to $20 \mathrm{ft}$ ) from a pickup truck. Two, 2-hr sampling periods, one beginning at sunrise and another commencing approximately 2 -hr prior to sunset, were used each day. Three sampling periods were normally required to complete all observations for each date.

The number of bite "units" of each species grazed was recorded as described by Reppert (1960). Unequal bite size due to different quantity available or different plant form was accounted for by estimating size of bite. If the actual animal bites were comparatively small, for a given species, two or more were recorded as one unit or bite.

Samples of fecal material were collected from 10 animals in each system during the same period that bite-count data was collected. Each sample was prepared for microscopic examination by adding hot water to the sample and blending for 1 or 2 minutes in a blender. This material was washed over a 200 mesh screen and a small portion of the washed material was used to make a microscope slide. Slides were prepared as described by Cavender and Hansen (1970). Fecal material was spread evenly on the glass slide using a clearing agent (Hertwig's solution). Most of the clearing agent was evaporated off by heating the slide over a bunsen burner. A cover slip was sealed on the slide using Hoyer's solution and the slide was then dried in an oven at $60^{\circ} \mathrm{C}$ for 3 days.

A reference collection was made of plant species found on the study area. Tissues of leaves, stems, flowers, and seeds of each species were mounted on slides in the same manner as the fecal material. Identification was based on epidermal tissue characteristics, such as guard cells, stomata, cell shape, and trichomes.

Two slides of fecal material were prepared for each animal. Each slide was viewed under a compound microscope at 100 power magnification. Ten fields or locations per slide were examined and the frequency of each species recorded. Frequency was converted to density using the tables prepared by Fracker and Brischle (1944). Relative density was calculated and used as an estimate of percent dry weight of each species in the diet (Sparks and Malechek 1968).

Dietary information from both methods was summarized into six categories: Texas wintergrass (Stipa leucotricha), sideoats grama (Bouteloua curtipendula) buffalograss (Buchloe dactyloides), other grasses, forbs, and shrubs.

\section{Results and Discussion}

Differences between grazing systems were minor and not significant $(P<.05)$; therefore, the diet data are reported without regard for grazing system. Figure 1 shows the month-by-month changes in cattle diet as determined by bite-count and fecal examination. Fecal samples from 10 animals per grazing system ( 20 per date) were sufficient to give satisfactory data as standard error values seldom exceeded $10 \%$ of the mean. Observations of five animals per grazing system for diet determination from bite-count proved sufficient to provide seasonal trends of major species in the diet. However, variation among animals was larger than for the fecal examination method as standard errors exceeded $20 \%$ of the mean about $1 / 4$ of the time. Significant differences (Fig. 1) that occurred between bite-count and fecal analysis were apparently because of the different lengths of the sampling periods. Fecal analysis estimates an animal's diet for up to a 6-day period, as it takes this long for ingesta to pass through the digestive tract (Church 1969). However, in this study the bite-count method provided an estimated of the diet for only 7 to $8 \mathrm{hr}$ out of a 2 -day period. The animals observed sometimes grazed in a small area of the pasture during this relatively short period, whereas during several days they grazed in many communities over the entire pasture.

An example of a difference in diet because of a short vs a long sampling period occurred in August 1972. For this date fecal analysis showed that the diet consisted of only $7 \%$ buffalograss, but the bite-count method showed $41 \%$ (Fig. 1). All cattle in that pasture grazed only in a buffalograssdominated plant community during the 2 day observation period. Thus, buffalograss was the only readily available species and the cattle mostly grazed on it. During the several days represented by the fecal collections, the cattle apparently had spent time in other communities eating other species. This kind of bias was essentially eliminated, except for the August 1972 date, because we observed animals scattered over the pasture rather than limiting observation to animals grazing only in one small area. Sampling intensively by ocular estimate to eliminate the few situations that might arise as described above probably would not be justified for the small increase in accuracy.

Some difficulty has been reported in identifying forbs with fecal analysis because they are so thoroughly digested (Storr 1961; Free et al. 1970). This could cause underestimation of forbs in the diet. However, underestimation did not appear serious in this study. Only 3 of the 33 diet comparisons between methods had significantly $(P<0.05)$ different amounts of forbs. Number of forb species detected in the diet by the two methods was about equal.

Early in the study it appeared fecal analysis overestimated the amount of silverleaf nightshade (Solanum elaeagnifolium) in the diet. According to fecal analyses, as much as a third of the diet on some dates was silverleaf nightshade. Not only did the bite-count method contradict such data, but the amount of silverleaf nightshade available for grazing also precluded such high percentages. Also it is poisonous to cattle and one $\mathrm{lb}$ is sufficient to kill a $1,000-\mathrm{lb}$ cow (Buck et al. 1960).

Silverleaf nightshade has large stellate trichomes. These trichomes are undigested and pass through the digestive tract in large numbers. Under the microscope, they appear so large (Fig. 2) that they blot out distinguishing characteristics of other species. Thus, only silverleaf nightshade might be noted as present in a microscope field, even though other species were also present. This results in overestimation of the silverleaf nightshade and underestimation of the other species in the diet. Examination of known species mixtures, determined by weight, confirmed that even trace amounts of silverleaf nightshade could yield a frequency as high as $25 \%$. Therefore, silverleaf nightshade was excluded from all the results of fecal analysis. No attempt was made to determine the degree of overestimation and then apply a correction factor because of the minute amount potentially in the diets. Other suspect forb species gave no detectable bias. However, a unique problem was discovered concerning mesquite beans. Fecal samples only were collected from an adjacent ranch operated by R.A. Brown. From January to March of 1973, no beans were available to the cattle on this ranch; but fecal samples collected during those months showed cattle diets with 8 to $14 \%$ mesquite beans. New reference slides of mesquite beans were made and compared with the slides from fecal samples. Mesquite beans were definitely in the feces, verified by two different observers. 

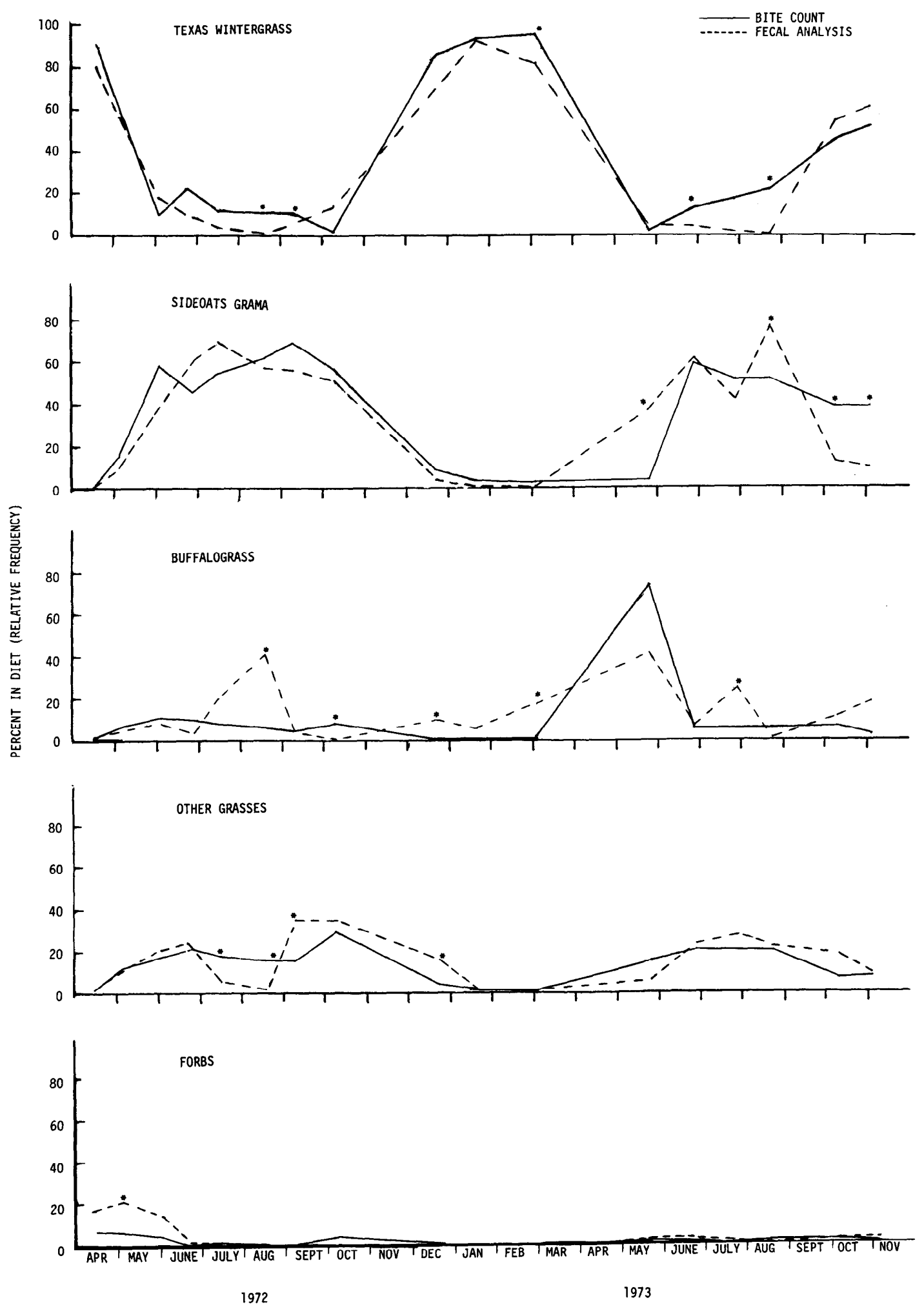

Fig. 1. Cattle diets as determined for the bite-count and fecal analysis methods. Asterisks (*) indicate significant differences (P<0.05) for the sampling period.

Dollahite and Anthony (1957) reported that mesquite beans had remained in the digestive tract of cattle as long as 9 months after consumption. They were frequently retained for 3 months. Mesquite trees growing on this adjacent ranch produced a large crop of beans in the fall of 1972, but by the end of December they were all gone, even from the ground.
Apparently, some were retained in the digestive tract from fall consumption and released in January, February, and March the following year. Mesquite beans were not produced in 1973 and no beans were observed by fecal analysis that fall nor the following winter. 


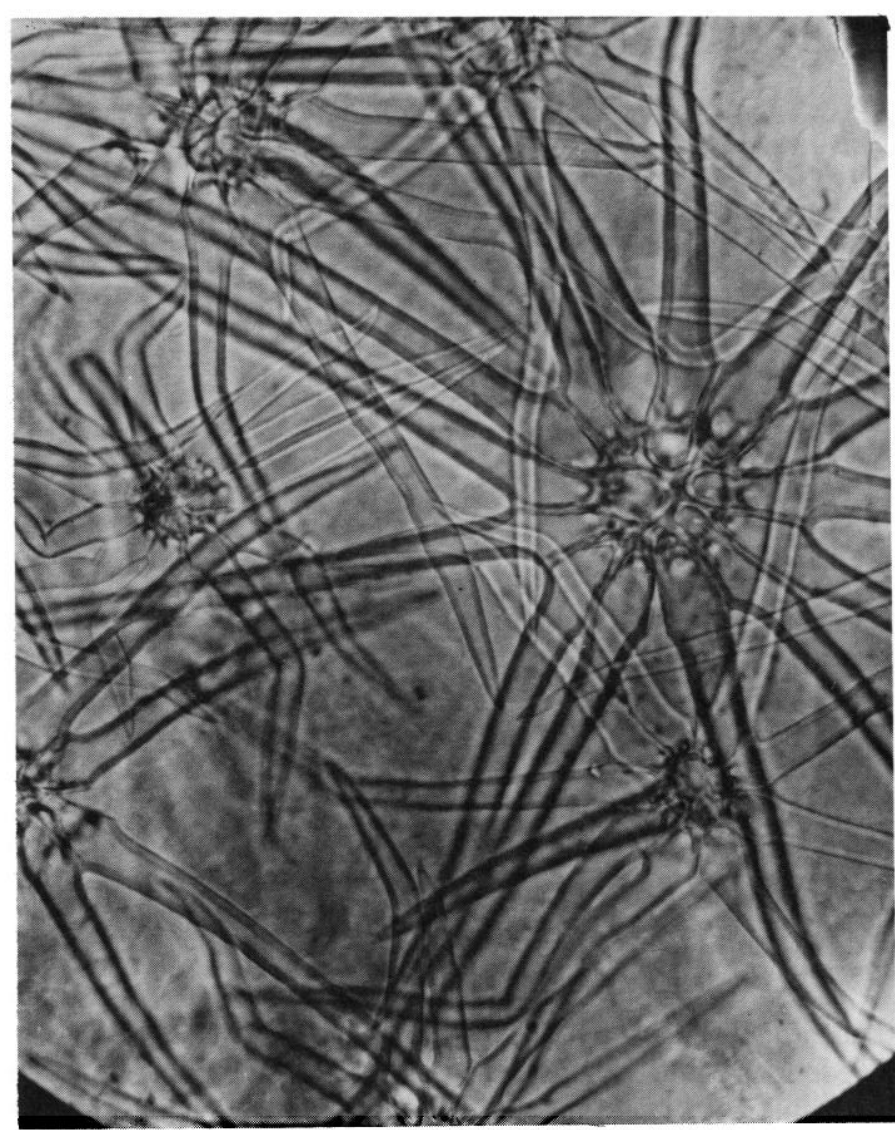

Fig. 2. Stellate trichomes of silverleaf nightshade (400X).

\section{Conclusions}

This study indicates that the bite-count and fecal analysis methods give similar results for major diet components. It would be difficult to use either the bite-count or the esophageal fistulae on animals grazing in the large brushinfested pastures commonly found in Texas. On the other hand, we collected fecal samples easily under such conditions. The fecal analysis method had the following additional advantages samples were collected with a minimum of field work; diets of wild animals (for another study) as well as domestic animals were obtained; it was not limited by weather or rough terrain; and it was not subject to observer bias, thus, it was relatively objective. Major disadvantages of the fecal analysis methods were: (1) forages with dense stellate trichomes could be overestimated; (2) mesquite beans were sometimes retained in the digestive tract for abnormally long periods indicating consumption when none occurred; (3) the laboratory phase required a trained technician and the work was tedious; and (4) it would be difficult to know which plant parts to collect and in what proportions for simulating diets for the chemical analyses needed for nutritional studies. Thus, the microscopic examination of animal feces cannot be considered the ultimate means of determining diets of range animals and it is probably more accurate for determining seasonal diets than for an individual date. However, it can be used with confidence in many areas where other methods cannot be used.

\section{Literature Cited}

Baumgartner, L.L., and A.C. Martin. 1939. Plant histology as an aid in squirrel food-habit studies. J. Wildl. Manage. 3:266-268.

Buck, W.B., J.W. Dollahite, and T.J. Allen. 1960. Solanum elaeagnifolium, silverleaf nightshade, poisoning in livestock. J. Amer. Vet. 137:348-351.

Cavender, Barbara R., and R.M. Hansen. 1970. The microscopic method for herbivore diet estimates and botanical analysis of litter and mulch at the Pawnee Site. Tech Rep. 18. Grassland Biome. USIBP. 9 p.

Church, D.C. 1969. Digestive physiology and nutrition of ruminants. Vol. I. Digestive physiology. Oregon State Univ., Corvallis. 316 p.

Cook, C.W. 1964. Symposium on nutrition of forage and pastures: Collecting forage samples representative of ingested materials of grazing animals for nutritional studies. J. Animal Sci. 23:265-270.

Dollahite, J.W., and W.V. Anthony. 1957. Malnutrition in cattle on an unbalanced diet of mesquite beans. Tex. Agr. Exp. Sta. Prog. Rep. 1931. 4 p.

Fracker, S.B., and H.A. Brischle. 1944. Measuring the local distribution of Ribes. Ecol. 25:283-303.

Free, James C., R.M. Hansen, and P.L. Sims. 1970. Estimating dry weights of food plants in feces of herbivores. J. Range Manage. 23:300-302.

Free, J.C., P.L. Sims, and R.M. Hansen. 1971. Methods of estimating dryweight composition in diets of steers. J. Animal Sci. 32:1003-1007.

Harris, Lorin E., C. Wayne Cook, and John E. Butcher. 1959. Symposium on forage evaluation: V. Intake and digestibility techniques and supplemental feeding in range forage evaluation. Agron. J. 51:226234.

Hercus, Barbara H. 1960. Plant cuticle as an aid to determining the diet of grazing animals. Proc. 8th Int. Grassl. Congr.8:443-447.

Malechek, J.C. 1966. Cattle diets on native and seeded ranges in the Ponderosa Pine zone of Colorado. U.S. Forest Service Res. Note. RM-77. $12 \mathrm{p}$.

McMahan, C.A. 1964. Comparative food habits of deer and three classes of livestock. J. Wildl. Manage. 28:798-808.

Regal, Vladimir. 1960. The evaluation of the quality of pasture grasses by the microscopic method. Proc. 8th Int. Grassl. Congr. 522-524.

Reppert, J.N. 1960. Forage preferences and grazing habits of cattle at the Eastern Colorado Range Station. J. Range Manage. 13:58-65.

Rice, R.W. 1970. Stomach content analysis: A comparison of the rumen vs esophageal techniques. 127-132. In: Range and Wildlife habitat evaluation: A research symposium. U.S. Dep. Agr. Misc. Pub. 1147. 220 p.

Sparks, D.R., and J.C. Malechek. 1968. Estimating percentage dry-weight in diets. J. Range Manage. 21:264-265.

Storr, G.M. 1961. Microscopic analysis of faeces, a technique for ascertaining the diet of herbivorous animals. Austral. J. Biol. Sci. 14 157-164.

Ward, A.L. 1970. Stomach content and fecal analysis: Methods of forage identification. P. 146-158. In: Range and wildlife habitat evaluation: A research symposium. U.S. Dep. Agr. Misc. Pub. 1147. 220 p. 